\title{
BMJ Open Associations of grip strength with retinal and choroidal thickness in patients with type 2 diabetes mellitus without retinopathy: a cross-sectional study
}

\author{
Zihan Qiu, ${ }^{1}$ Wei Wang (D) , ${ }^{1}$ Yan Tan, ${ }^{1}$ Miao He, ${ }^{2}$ Langhua Wang, ${ }^{1}$ Yuting Li, ${ }^{1}$ \\ Xia Gong, ${ }^{1}$ Wenyong Huang ${ }^{1}$
}

To cite: Qiu Z, Wang W, Tan Y, et al. Associations of grip strength with retinal and choroidal thickness in patients with type 2 diabetes mellitus without retinopathy: a crosssectional

study. BMJ Open

2020;10:e036782. doi:10.1136/ bmjopen-2020-036782

- Prepublication history and additional material for this paper are available online. To view these files, please visit the journal online (http://dx.doi. org/10.1136/bmjopen-2020036782).

Received 03 January 2020 Revised 02 April 2020 Accepted 03 April 2020

Check for updates

(c) Author(s) (or their employer(s)) 2020. Re-use permitted under CC BY-NC. No commercial re-use. See rights and permissions. Published by BMJ.

${ }^{1}$ State Key Laboratory of Ophthalmology, Zhongshan Ophthalmic Center, Sun Yat-sen University, Guangzhou, China ${ }^{2}$ Department of Ophthalmology, Guangdong General Hospital, Guangzhou, China

Correspondence to Dr Wei Wang; zoc_wangwei@yahoo.com and Professor Wenyong Huang; andyhwyz@aliyun.com

\section{ABSTRACT}

Objective To evaluate the associations of grip strength with retinal or choroidal thickness in patients with type 2 diabetes mellitus without retinopathy.

Design Observational study-cross-sectional design.

Setting and participants This study included the

Chinese patients with type 2 diabetes without retinopathy registered in the community health system in Guangzhou, China.

Measures The grip strength in both hands were measured by using a dynamometer. The retinal and choroidal thickness in macular region stratified by Early Treatment Diabetic Retinopathy Study (ETDRS) sectors were measured by a swept-source optical coherence tomography.

Results A total of 1029 patients were included. Both retinal thickness and choroidal thickness decreased with the lower quartile of grip strength. Regression analyses indicated that the average retinal and choroidal thickness increased by $0.14 \mu \mathrm{m}(95 \% \mathrm{Cl}: 0.03$ to $0.25 \mu \mathrm{m}, \mathrm{p}=0.011)$ and $0.57 \mu \mathrm{m}$ ( $95 \% \mathrm{Cl}: 0.03$ to $1.11 \mu \mathrm{m}, \mathrm{p}=0.037)$, respectively, for each additional kilogram of grip strength following adjustment for age and sex. Further adjustments were made for axial length, haemoglobin A1c, length of time the patient had diabetes, insulin usage, height, weight and systolic and diastolic blood pressure, which resulted in an average retinal and choroidal thickness increase of $0.13 \mu \mathrm{m}(95 \% \mathrm{Cl}: 0.02$ to $0.24 \mu \mathrm{m}, \mathrm{p}=0.024)$ and $0.65 \mu \mathrm{m}$ (95\% Cl: 0.13 to $1.16 \mu \mathrm{m}, p=0.013$ ), respectively, for each additional kilogram of grip strength. Consistent results were obtained in the analyses in ETDRS 9 sectors.

Conclusion Lower hand grip strength was found to be significantly associated with thinner retinal and choroidal layers in patients with diabetes. Grip strength may provide a useful and easily administered indicator of retinal status in patients with diabetes.

\section{INTRODUCTION}

Diabetes has become a growing health problem, which can cause cardiovascular diseases and death. ${ }^{1}$ Diabetic retinopathy (DR) may lead to severe visual disorders. It was
Strengths and limitations of this study

- There is a large sample for analysis.

- The hand grip strength and ocular parameters measured were standardised.

- The cross-sectional design of the study prevents dynamic analysis.

- Only Chinese in urban area were included.

The findings may not generalise to types 1 diabetes mellitus and patients with diabetic retinopathy.

estimated that diabetes affected 415 million adults in 2015 and will affect 642 million people in 2040. ${ }^{2}$ Among the patients with diabetes, $34.6 \%$ had DR, accounting for $2.6 \%$ of all blindness. ${ }^{34}$ At present, optical coherence tomography (OCT) examinations used in clinics provide an accurate reflection of fundus changes, but widespread performance of this approach is expensive and inconvenient.

Grip strength is an indicator of upper limb muscle function and tension, and it is one of the important indicators of ageing in the human population. ${ }^{5}$ Hand grip strength (HGS) is easy to measure and has great clinical significance. It was well documented that low grip strength was related to higher risk of type 2 diabetes. ${ }^{67}$ Furthermore, reduced grip strength was independent predictor of pre-diabetes in Chinese adults. ${ }^{8}$ Fukuda $e t$ at reported that lower muscle quality was related with higher odds of DR in patients with diabetes. Evidence has suggested that the size of a patients' retinal artery is independently related to grip strength in elderly patients living in Scotland. ${ }^{10}$ The Beaver Dam Eye Study indicated that men with increased HGS had lower odds of early and 

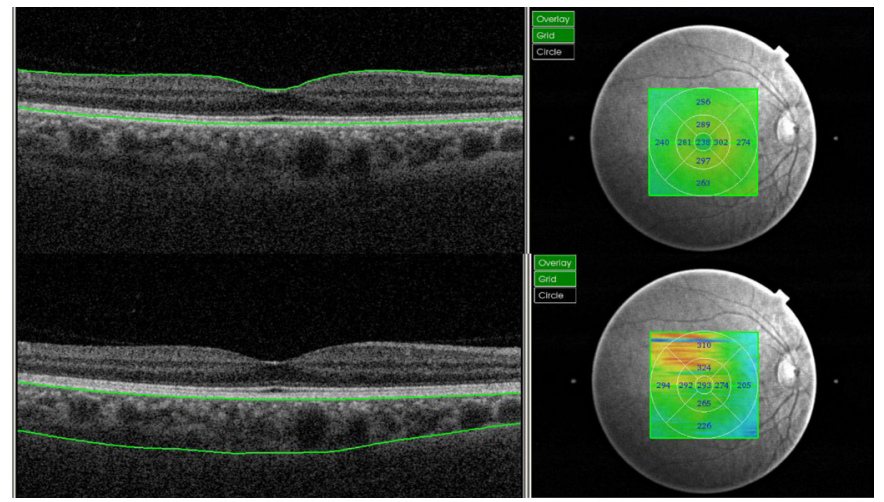

Figure 1 Illustration of measurements of retinal and choroidal thickness in Early Treatment Diabetic Retinopathy Study 9 sectors using swept-source optical coherence tomography. (A) Retinal thickness; (B) choroidal thickness.

later age-related macular degeneration by $28 \%$ and $55 \%$, respectively. $^{11}$

The retina and choroid are important layers in the eyeball, and retinal thickness (RT) and choroidal thickness (CT) are both useful indicators of overall eye health. ${ }^{12}$ The choroid provides the retinal pigment epithelium with metabolic support and nourishes the optic nerve, choroid and outer retina. The normality of choroidal structure and function plays a key role in the function of the retina. ${ }^{13}$ Abnormalities of RT and CT have been involved in the pathogenesis of DR. The choroid in patients with diabetes but without DR is thinner than that in healthy people but thicker than that in patients with DR. ${ }^{14}$ Thinning of the choroid is considered to be an early sign of diabetes in patients with no clinical DR. ${ }^{15}$ To the best of our knowledge, the potential associations of grip strength with RT or CT have not been explored in previous studies. Therefore, to address this important consideration, the objective of this study was to evaluate the associations of grip strength with RT and CT in patients with diabetes using swept-source optical coherence tomography (SS-OCT).

\section{METHODS}

Subjects

This is a cross-sectional study, which was conducted at the Zhongshan Ophthalmic Center (ZOC), affiliated to Sun Yat-sen University, China. The study was performed in accordance with the tenets of the Helsinki Declaration.

Table 1 Demographic and clinical characteristics of patients with diabetes without retinopathy

\begin{tabular}{|c|c|c|c|c|c|c|}
\hline \multirow[b]{2}{*}{ Characteristics } & \multirow[b]{2}{*}{ All } & \multicolumn{4}{|c|}{ Quarter of grip strength } & \multirow[b]{2}{*}{$P$ value } \\
\hline & & Q1 (lowest) & Q2 & Q3 & Q4 (highest) & \\
\hline No of subjects & 1029 & 258 & 260 & 255 & 256 & - \\
\hline Female, n (\%) & $616(59.86)$ & $224(86.82)$ & 215 (82.69) & $129(50.59)$ & $48(18.75)$ & $<0.001$ \\
\hline Use of insulin, $n(\%)$ & $163(16.03)$ & $40(15.69)$ & $39(15.18)$ & $39(15.42)$ & $45(17.86)$ & 0.836 \\
\hline Age, years & $64.5 \pm 7.7$ & $66.2 \pm 7.2$ & $64.7 \pm 7.4$ & $63.6 \pm 7.8$ & $63.6 \pm 8.1$ & $<0.001$ \\
\hline Duration of diabetes, years & $8.1 \pm 6.6$ & $8.7 \pm 6.7$ & $8.3 \pm 6.7$ & $7.5 \pm 6.3$ & $8.1 \pm 6.6$ & 0.214 \\
\hline $\mathrm{HbA} 1 \mathrm{c}, \%$ & $6.8 \pm 1.3$ & $6.8 \pm 1.2$ & $6.7 \pm 1.3$ & $6.8 \pm 1.3$ & $6.9 \pm 1.4$ & 0.507 \\
\hline Height, $\mathrm{cm}$ & $160.1 \pm 8.1$ & $155.4 \pm 6.9$ & $157.8 \pm 6.7$ & $161.7 \pm 6.9$ & $165.5 \pm 8.0$ & $<0.001$ \\
\hline Weight, kg & $63.7 \pm 11.5$ & $59.5 \pm 9.9$ & $60.7 \pm 9.9$ & $65.0 \pm 10.0$ & $69.7 \pm 13.0$ & $<0.001$ \\
\hline Systolic blood pressure, $\mathrm{mm} \mathrm{Hg}$ & $133.7 \pm 18.5$ & $132.6 \pm 19.2$ & $134.3 \pm 18.4$ & $134.1 \pm 18.2$ & $133.9 \pm 18.1$ & 0.714 \\
\hline Diastolic blood pressure, $\mathrm{mm} \mathrm{Hg}$ & $70.7 \pm 10.4$ & $69.6 \pm 10.8$ & $70.3 \pm 9.9$ & $71.4 \pm 10.0$ & $71.4 \pm 10.9$ & 0.112 \\
\hline Total cholesterol, $\mathrm{mmol} / \mathrm{L}$ & $4.8 \pm 1.0$ & $4.9 \pm 1.0$ & $5.0 \pm 1.1$ & $4.8 \pm 1.0$ & $4.6 \pm 1.0$ & 0.001 \\
\hline Serum creatinine, $\mu \mathrm{mol} / \mathrm{L}$ & $70.3 \pm 19.3$ & $68.0 \pm 20.2$ & $65.2 \pm 19.8$ & $71.3 \pm 18.3$ & $76.6 \pm 17.0$ & $<0.001$ \\
\hline $\mathrm{HDL}-\mathrm{C}, \mathrm{mmol} / \mathrm{L}$ & $1.3 \pm 0.4$ & $1.4 \pm 0.4$ & $1.4 \pm 0.4$ & $1.3 \pm 0.4$ & $1.2 \pm 0.4$ & $<0.001$ \\
\hline LDL-C, mmol/L & $3.1 \pm 0.9$ & $3.1 \pm 0.9$ & $3.2 \pm 1.0$ & $3.1 \pm 0.9$ & $3.0 \pm 0.9$ & 0.122 \\
\hline Triglycerides, $\mathrm{mmol} / \mathrm{L}$ & $2.3 \pm 1.6$ & $2.4 \pm 1.6$ & $2.3 \pm 1.5$ & $2.3 \pm 1.7$ & $2.3 \pm 1.7$ & 0.976 \\
\hline C reactive protein, mg/L & $2.7 \pm 7.4$ & $2.8 \pm 3.5$ & $3.1 \pm 12.3$ & $2.4 \pm 3.8$ & $2.4 \pm 6.5$ & 0.658 \\
\hline Microalbuminuria, $\mathrm{mg} / \mathrm{mL}$ & $4.1 \pm 14.9$ & $4.7 \pm 14.7$ & $4.9 \pm 23.0$ & $3.3 \pm 8.0$ & $3.6 \pm 9.0$ & 0.530 \\
\hline BCVA, logMAR & $0.2 \pm 0.1$ & $0.2 \pm 0.1$ & $0.2 \pm 0.1$ & $0.2 \pm 0.2$ & $0.2 \pm 0.1$ & 0.133 \\
\hline Intraocular pressure, mm Hg & $16.2 \pm 2.7$ & $16.4 \pm 2.8$ & $16.2 \pm 2.6$ & $15.9 \pm 2.7$ & $16.1 \pm 2.8$ & 0.278 \\
\hline Central corneal thickness, $\mu \mathrm{m}$ & $546.1 \pm 31.5$ & $545.8 \pm 29.6$ & $544.8 \pm 30.8$ & $542.8 \pm 33.1$ & $550.9 \pm 31.9$ & 0.026 \\
\hline Axial length, mm & $23.6 \pm 1.1$ & $23.4 \pm 1.0$ & $23.5 \pm 1.2$ & $23.6 \pm 1.1$ & $23.8 \pm 1.0$ & $<0.001$ \\
\hline
\end{tabular}

Bold indicates statistically significant.

BCVA, best-corrected visual acuity; HbA1c, haemoglobin A1c; HDL-C, high-density lipoprotein cholesterol; LDL-C, low-density lipoprotein cholesterol. 
Table 2 Differences in retinal and choroidal thickness among groups by quartiles of grips strength

\begin{tabular}{|c|c|c|c|c|c|c|}
\hline Parameters & All & Quartile 1 & Quartile 2 & Quartile 3 & Quartile 4 & $P$ value \\
\hline \multicolumn{7}{|l|}{ Retinal thickness } \\
\hline Outer superior, $\mu \mathrm{m}$ & $265.8 \pm 18.9$ & $261.8 \pm 15.6$ & $265.9 \pm 20.0$ & $266.6 \pm 22.7$ & $268.8 \pm 15.9$ & $<0.001$ \\
\hline Outer temporal, $\mu \mathrm{m}$ & $251.5 \pm 16.9$ & $247.4 \pm 15.1$ & $250.5 \pm 18.2$ & $252.6 \pm 17.1$ & $255.5 \pm 15.8$ & $<0.001$ \\
\hline Inner temporal, $\mu \mathrm{m}$ & $288.8 \pm 17.7$ & $284.4 \pm 15.8$ & $286.8 \pm 17.2$ & $290.2 \pm 18.8$ & $294.0 \pm 17.6$ & $<0.001$ \\
\hline Inner nasal, $\mu \mathrm{m}$ & $300.9 \pm 18.4$ & $296.4 \pm 16.1$ & $299.6 \pm 18.9$ & $301.9 \pm 18.5$ & $305.6 \pm 18.8$ & $<0.001$ \\
\hline Outer nasal, $\mu \mathrm{m}$ & $280.0 \pm 17.9$ & $276.3 \pm 15.8$ & $279.2 \pm 18.7$ & $280.6 \pm 18.6$ & $284.0 \pm 17.6$ & $<0.001$ \\
\hline Inner inferior, $\mu \mathrm{m}$ & $297.2 \pm 19.6$ & $292.8 \pm 17.2$ & $295.8 \pm 20.5$ & $297.9 \pm 19.7$ & $302.5 \pm 19.8$ & $<0.001$ \\
\hline Outer inferior, $\mu \mathrm{m}$ & $255.8 \pm 19.0$ & $253.1 \pm 15.1$ & $255.7 \pm 24.3$ & $256.6 \pm 18.1$ & $257.6 \pm 17.0$ & 0.0483 \\
\hline Average, $\mu \mathrm{m}$ & $274.4 \pm 15.3$ & $270.2 \pm 12.9$ & $273.4 \pm 15.6$ & $275.6 \pm 16.1$ & $278.7 \pm 15.1$ & $<0.001$ \\
\hline Inner superior, $\mu \mathrm{m}$ & $202.0 \pm 81.5$ & $187.2 \pm 81.1$ & $200.2 \pm 79.5$ & $201.1 \pm 82.1$ & $219.7 \pm 80.2$ & $<0.001$ \\
\hline Outer temporal, $\mu \mathrm{m}$ & $173.9 \pm 65.0$ & $159.1 \pm 59.6$ & $177.0 \pm 62.8$ & $170.6 \pm 67.9$ & $189.0 \pm 66.2$ & $<0.001$ \\
\hline Inner temporal, $\mu \mathrm{m}$ & $195.4 \pm 74.4$ & $179.3 \pm 69.1$ & $199.1 \pm 72.5$ & $191.1 \pm 77.3$ & $212.3 \pm 74.9$ & $<0.001$ \\
\hline Central field, $\mu \mathrm{m}$ & $201.9 \pm 83.8$ & $184.9 \pm 80.4$ & $202.6 \pm 83.2$ & $199.1 \pm 85.8$ & $221.0 \pm 82.4$ & $<0.001$ \\
\hline Inner nasal, $\mu \mathrm{m}$ & $189.6 \pm 85.5$ & $171.4 \pm 81.0$ & $190.6 \pm 85.0$ & $189.5 \pm 86.5$ & $207.2 \pm 86.1$ & $<0.001$ \\
\hline Outer nasal, $\mu \mathrm{m}$ & $149.9 \pm 79.5$ & $132.9 \pm 72.0$ & $151.5 \pm 80.4$ & $153.3 \pm 81.5$ & $162.0 \pm 81.4$ & $<0.001$ \\
\hline Inner inferior, $\mu \mathrm{m}$ & $188.2 \pm 83.5$ & $166.4 \pm 77.2$ & $190.5 \pm 83.6$ & $187.6 \pm 83.4$ & $208.6 \pm 84.7$ & $<0.001$ \\
\hline Outer inferior, $\mu \mathrm{m}$ & $167.0 \pm 78.1$ & $147.0 \pm 70.2$ & $169.1 \pm 78.5$ & $166.8 \pm 79.3$ & $185.3 \pm 79.7$ & $<0.001$ \\
\hline Average, $\mu \mathrm{m}$ & $184.5 \pm 73.6$ & $167.4 \pm 69.1$ & $185.5 \pm 72.9$ & $183.6 \pm 74.8$ & $201.6 \pm 73.8$ & $<0.001$ \\
\hline
\end{tabular}

Bold indicates statistically significant.

Informed consent form was obtained from all subjects before entering.

Eligible subjects included ocular treatment-naive patients with type 2 diabetes between the ages of 30 and 80 years. Participants were excluded if they had any of the following conditions: evidence of DR based on ETDRS 7 photography, an axial length (AL) $>30 \mathrm{~mm}$, a spherical equivalent $>-10 \mathrm{D}$, a cylinder degree $\geq 3.0 \mathrm{D}$, anisometropia of $\geq 2.0 \mathrm{D}$, a $\mathrm{C} / \mathrm{D}$ ratio $\geq 0.5$ or inter-eye asymmetry $\geq 0.2$, a history of ocular disease (except for light cataract) or trauma, a history of ocular laser or surgical interventions and/or a history of systemic diseases such as stroke, chronic kidney disease, cancer or chronic obstructive pulmonary disease, history of diabetic polyneuropathy. $^{16}$

\section{Systemic measurements}

Standardised questionnaires were used to obtain the information of age, sex, length of time patient has had diabetes, medication compliance, presence of other systematic chronic diseases and risk factors. Standardised protocols were followed to measure the systolic blood pressure (SBP), diastolic blood pressure (DBP), height and weight. Blood and urine samples were obtained from all patients, and they were analysed for the following parameters: serum creatinine, microalbuminuria, haemoglobin A1c (HbA1c), total cholesterol (TC), triglyceride (TG), high-density lipoprotein cholesterol (HDL-C) and low-density lipoprotein cholesterol. The most frequently studied tag single nucleotide polymorphisms (rs2228570) of vitamin D receptor was genotyped using TaqMan assays.

\section{Hand grip strength}

HGS is a proxy of muscle mass and strength. A commercial dynamometer (Yuejian WL-1000, Nantong, China) was used to measure HGS twice for each hand according to standardised protocol. HGS was obtained in a standing position, except for those with physical limitations. Participants' shoulders were retracted and rotated, elbows were bent 90 degrees, and forearms and wrists were in a horizontal position. The dominant or non-dominant hand was randomly adopted to test first by squeezing the dynamometer handle as hard as possible for a few seconds and then repeat the test with the other hand. Each hand is tested twice, and the two tests are alternated. The average value of the four tests was used for statistical analysis. Subjects who had undergone hand surgery or had severe hand pain or wrist arthritis in the past 6 months were excluded. 

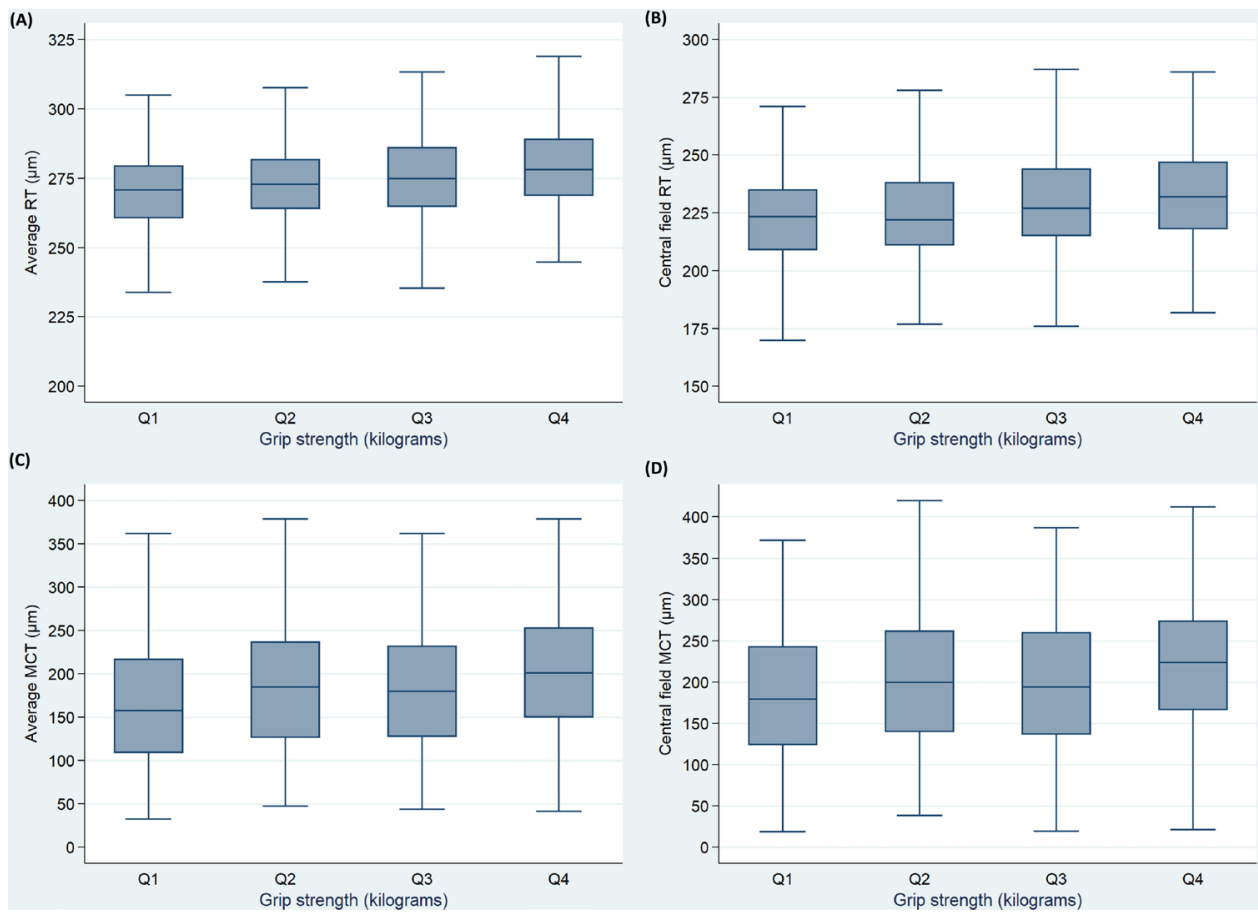

Figure 2 Boxplots showing the distribution of retinal thickness (RT) and choroidal thickness stratified by quartiles of the hand grip strength. (A) Average RT versus grip strength; (B) RT in central field versus grip strength; (C) average choroidal thickness versus grip strength; (D) choroidal thickness in central field versus grip strength. MCT, mean choroidal thickness.

\section{Ocular examination}

Comprehensive ocular examinations were conducted for all participants, including slit-lamp biomicroscopy, ophthalmoscopy, visual acuity and intraocular pressure. The optical low-coherence reflectometry (Lenstar LS900; Haag-Streit AG, Koeniz, Switzerland) was used to measure the AL, anterior chamber depth and lens thickness. The autorefractor (KR8800; Topcon, Tokyo, Japan) was used to measure refraction after pupil dilation. The digital fundus camera (Canon CR-2, Tokyo, Japan) was used to obtain standardised retinal images in ETDRS 7 fields after pupil dilation. DR was diagnosed using International Clinical Diabetic Retinopathy and Diabetic Macular Oedema Disease Severity Scales.

\section{SS-OCT imaging}

The retinal and choroidal images were obtained by using a commercial SS-OCT device (DRI OCT-2 Triton; Topcon), which has the speed of 100000 A-scans/s and axial resolution of $8 \mu \mathrm{m}$. The imaging method has been described elsewhere in detail. ${ }^{17}$ The $7 \times 7 \mathrm{~mm}$ raster scan protocol was used to obtain 3-D images centring on the macula; the RT and CT in ETDRS 9 sectors were calculated automatically by the built-in software. The ETDRS sector divides the macular into two rings, including the inner and outer rings, which were $1-3 \mathrm{~mm}$ and $3-6 \mathrm{~mm}$, respectively (figure 1 ). In addition, the average $\mathrm{RT}$ and CT in all nine grids were calculated. An experienced technician performed all the OCT scans. All participants confirmed that they had not taken caffeine, alcohol and medications $\geq 24$ hours before OCT imaging. The images with any evidence of any of the following conditions were excluded: image quality index $\leq 50$, eye movement, artefacts, segmentation failure.

\section{Statistical analyses}

According to the scores of grip strength from low to high, the participants were divided into four groups: Q1, Q2, Q3 and Q4. The Kolmogorov-Smirnov test was used to confirm the normal distribution. The Fisher exact test was used for categorical variables. The analysis of variance test was used to evaluate the intergroup difference of demographic, systemic and ocular parameters. Bivariate scatter plots were created to display the potential factors affecting RT and CT. Linear regression analyses were used to assess the association of RT and CT with demographic or ocular parameters, such as age, sex, AL, HbAlc and other parameters previously mentioned. ${ }^{17}$ Univariate analysis showed that the predictive variables were significant, which were then entered into the final multivariate equation. The statistical significance cut-off was set at 0.05. All analyses were conducted using Stata V.14.0 software (Stata Corporation).

\section{RESULTS}

A total of 1029 patients without any evidence of DR were included in the present study, which included 616 $(59.86 \%)$ women with an average age of $64.5 \pm 7.7$ years. Table 1 presents the features of the participants. Differences in gender, age, height, weight, TC, serum creatinine, HDL-C, CCT and AL between each group were found to be statistically significant $(\mathrm{p}<0.05)$. 
Table 3 Association of grip strength and retinal thickness by multivariate linear regression analyses

\begin{tabular}{|c|c|c|c|c|c|c|}
\hline \multirow[b]{2}{*}{ Retinal thickness } & \multicolumn{3}{|l|}{ Model 1* } & \multicolumn{3}{|l|}{ Model 2† } \\
\hline & Coefficient & $95 \% \mathrm{Cl}$ & $P$ value & Coefficient & $95 \% \mathrm{Cl}$ & $P$ value \\
\hline \multicolumn{7}{|l|}{ Average, $\mu \mathrm{m}$} \\
\hline Quantile 1 & 1.00 (Ref) & & & 1.00 (Ref) & & \\
\hline Quantile 2 & 2.16 & $(-0.28$ to 4.61$)$ & 0.083 & 1.71 & $(-0.75$ to 4.168$)$ & 0.174 \\
\hline Quantile 3 & 2.10 & (-0.48 to 4.69$)$ & 0.111 & 1.33 & $(-1.28$ to 3.935$)$ & 0.319 \\
\hline Quantile 4 & 3.68 & (0.81 to 6.55$)$ & 0.012 & 3.35 & (0.44 to 6.256$)$ & 0.024 \\
\hline Per $1 \mathrm{~kg}$ increase & 0.14 & (0.03 to 0.25$)$ & 0.011 & 0.13 & (0.02 to 0.24$)$ & 0.024 \\
\hline \multicolumn{7}{|l|}{ Central field, $\mu \mathrm{m}$} \\
\hline Quantile 1 & 1.00 (Ref) & & & 1.00 (Ref) & & \\
\hline Quantile 2 & 2.50 & $(-1.42$ to 6.43$)$ & 0.211 & 1.90 & (-2.04 to 5.831$)$ & 0.345 \\
\hline Quantile 3 & 5.08 & (0.92 to 9.24$)$ & 0.017 & 4.62 & (0.45 to 8.790$)$ & 0.030 \\
\hline Quantile 4 & 4.53 & $(-0.08$ to 9.13$)$ & 0.054 & 4.15 & $(-0.49$ to 8.801$)$ & 0.080 \\
\hline Per $1 \mathrm{~kg}$ increase & 0.16 & (-0.02 to 0.33$)$ & 0.082 & 0.15 & $(-0.03$ to 0.32$)$ & 0.109 \\
\hline \multicolumn{7}{|l|}{ Outer superior, $\mu \mathrm{m}$} \\
\hline Quantile 1 & 1.00 (Ref) & & & 1.00 (Ref) & & \\
\hline Quantile 2 & 3.03 & $(-0.08$ to 6.14$)$ & 0.056 & 2.65 & $(-0.43$ to 5.725$)$ & 0.091 \\
\hline Quantile 3 & 2.49 & (-0.80 to 5.78$)$ & 0.138 & 1.47 & $(-1.79$ to 4.734$)$ & 0.375 \\
\hline Quantile 4 & 4.44 & (0.80 to 8.08 ) & 0.017 & 3.74 & (0.11 to 7.373$)$ & 0.043 \\
\hline Per $1 \mathrm{~kg}$ increase & 0.19 & (0.05 to 0.33 ) & 0.008 & 0.16 & (0.02 to 0.30$)$ & 0.022 \\
\hline \multicolumn{7}{|l|}{ Outer inferior, $\mu \mathrm{m}$} \\
\hline Quantile 1 & 1.00 (Ref) & & & 1.00 (Ref) & & \\
\hline Quantile 2 & 1.49 & (-1.65 to 4.62$)$ & 0.352 & 1.27 & $(-1.83$ to 4.373$)$ & 0.420 \\
\hline Quantile 3 & 1.17 & $(-2.15$ to 4.49$)$ & 0.489 & 0.49 & $(-2.79$ to 3.778$)$ & 0.768 \\
\hline Quantile 4 & 1.86 & (-1.82 to 5.53$)$ & 0.321 & 1.90 & $(-1.76$ to 5.561$)$ & 0.308 \\
\hline Per $1 \mathrm{~kg}$ increase & 0.06 & $(-0.08$ to 0.21$)$ & 0.368 & 0.06 & $(-0.08$ to 0.20$)$ & 0.377 \\
\hline \multicolumn{7}{|l|}{ Outer nasal, $\mu \mathrm{m}$} \\
\hline Quantile 1 & 1.00 (Ref) & & & 1.00 (Ref) & & \\
\hline Quantile 2 & 1.72 & $(-1.16$ to 4.60$)$ & 0.243 & 1.63 & $(-1.20$ to 4.475$)$ & 0.259 \\
\hline Quantile 3 & 1.16 & $(-1.89$ to 4.21$)$ & 0.457 & 0.55 & $(-2.46$ to 3.557$)$ & 0.721 \\
\hline Quantile 4 & 3.64 & (0.26 to 7.02$)$ & 0.035 & 3.46 & (0.11 to 6.810$)$ & 0.043 \\
\hline Per $1 \mathrm{~kg}$ increase & 0.14 & (0.01 to 0.27 ) & 0.031 & 0.14 & (0.01 to 0.26$)$ & 0.040 \\
\hline \multicolumn{7}{|l|}{ Outer temporal, $\mu \mathrm{m}$} \\
\hline Quantile 1 & 1.00 (Ref) & & & 1.00 (Ref) & & \\
\hline Quantile 2 & 1.94 & $(-0.78$ to 4.66$)$ & 0.162 & 1.83 & $(-0.80$ to 4.449$)$ & 0.172 \\
\hline Quantile 3 & 1.88 & $(-1.01$ to 4.76$)$ & 0.202 & 1.02 & $(-1.76$ to 3.799$)$ & 0.472 \\
\hline Quantile 4 & 3.36 & (0.17 to 6.56$)$ & 0.039 & 2.72 & $(-0.37$ to 5.818$)$ & 0.085 \\
\hline Per $1 \mathrm{~kg}$ increase & 0.14 & (0.02 to 0.27 ) & 0.022 & 0.12 & (0.00 to 0.24$)$ & 0.053 \\
\hline \multicolumn{7}{|l|}{ Inner superior, $\mu \mathrm{m}$} \\
\hline Quantile 1 & 1.00 (Ref) & & & 1.00 (Ref) & & \\
\hline Quantile 2 & 3.62 & (0.61 to 6.63$)$ & 0.018 & 3.18 & (0.13 to 6.226$)$ & 0.041 \\
\hline Quantile 3 & 2.39 & (-0.80 to 5.58$)$ & 0.142 & 1.68 & $(-1.54$ to 4.912$)$ & 0.306 \\
\hline Quantile 4 & 4.52 & (0.99 to 8.05 ) & 0.012 & 4.46 & (0.86 to 8.053 ) & 0.015 \\
\hline Per $1 \mathrm{~kg}$ increase & 0.15 & (0.01 to 0.29 ) & 0.032 & 0.14 & (0.00 to 0.28$)$ & 0.046 \\
\hline \multicolumn{7}{|l|}{ Inner inferior, $\mu \mathrm{m}$} \\
\hline Quantile 1 & 1.00 (Ref) & & & 1.00 (Ref) & & \\
\hline
\end{tabular}


Table 3 Continued

\begin{tabular}{|c|c|c|c|c|c|c|}
\hline \multirow[b]{2}{*}{ Retinal thickness } & \multicolumn{3}{|l|}{ Model 1* } & \multicolumn{3}{|l|}{ Model 2† } \\
\hline & Coefficient & $95 \% \mathrm{Cl}$ & $P$ value & Coefficient & $95 \% \mathrm{Cl}$ & $P$ value \\
\hline Quantile 2 & 1.73 & $(-1.47$ to 4.94$)$ & 0.289 & 0.88 & (-2.29 to 4.059$)$ & 0.586 \\
\hline Quantile 3 & 1.01 & $(-2.39$ to 4.40$)$ & 0.561 & 0.01 & (-3.36 to 3.377$)$ & 0.995 \\
\hline Quantile 4 & 3.51 & $(-0.25$ to 7.27$)$ & 0.067 & 3.38 & $(-0.37$ to 7.133$)$ & 0.077 \\
\hline Per $1 \mathrm{~kg}$ increase & 0.15 & (0.00 to 0.29 ) & 0.048 & 0.13 & $(-0.01$ to 0.28$)$ & 0.069 \\
\hline \multicolumn{7}{|l|}{ Inner nasal, $\mu \mathrm{m}$} \\
\hline Quantile 1 & 1.00 (Ref) & & & 1.00 (Ref) & & \\
\hline Quantile 2 & 2.15 & $(-0.89$ to 5.18$)$ & 0.165 & 1.40 & ( -1.67 to 4.473$)$ & 0.372 \\
\hline Quantile 3 & 2.02 & $(-1.19$ to 5.24$)$ & 0.217 & 1.25 & $(-2.00$ to 4.509$)$ & 0.451 \\
\hline Quantile 4 & 3.86 & (0.30 to 7.42$)$ & 0.034 & 3.50 & $(-0.13$ to 7.124$)$ & 0.059 \\
\hline Per $1 \mathrm{~kg}$ increase & 0.15 & (0.01 to 0.28$)$ & 0.038 & 0.13 & $(-0.01$ to 0.27$)$ & 0.067 \\
\hline \multicolumn{7}{|l|}{ Inner temporal, $\mu \mathrm{m}$} \\
\hline Quantile 1 & 1.00 (Ref) & & & 1.00 (Ref) & & \\
\hline Quantile 2 & 1.34 & $(-1.55$ to 4.23$)$ & 0.363 & 0.66 & $(-2.27$ to 3.577$)$ & 0.660 \\
\hline Quantile 3 & 1.82 & $(-1.24$ to 4.88$)$ & 0.243 & 0.91 & $(-2.18$ to 4.008$)$ & 0.563 \\
\hline Quantile 4 & 3.40 & (0.02 to 6.79$)$ & 0.049 & 2.84 & (-0.61 to 6.287$)$ & 0.106 \\
\hline Per $1 \mathrm{~kg}$ increase & 0.15 & (0.02 to 0.28 ) & 0.021 & 0.13 & (0.00 to 0.26$)$ & 0.055 \\
\hline
\end{tabular}

Bold indicates statistically significant.

*Model 1: adjusted for age and sex.

†Model 2: adjusted for age, gender, axial length, haemoglobin A1c, diabetes duration, use of insulin, height, weight, systolic blood pressure and diastolic blood pressure.

Table 2 presents the distribution of RT and CT in each sector across groups. The RT and CT differed significantly among the four groups $(\mathrm{p}<0.001, \mathrm{RT}$ in the outer inferior $\mathrm{p}=0.0483$ ). Both RT and CT decreased in the lower quartile of HGS (figure 2).

Table 3 presents the association between HGS and RT based on multivariable regression analyses. After adjusting for age and gender, the average RT and CT decreased by $0.14 \mu \mathrm{m}(\mathrm{p}=0.011)$ and $0.57 \mu \mathrm{m}(\mathrm{p}=0.037)$, respectively, for $1 \mathrm{~kg}$ of reduced HGS. There was a statistically significant association between HGS and RT in at least one group in each region except the outer inferior. After adjusting for age, sex, AL, HbAlc, duration of diabetes, insulin usage, height, weight and SBP and DBP, the average RT and CT decreased by $0.13 \mu \mathrm{m}(\mathrm{p}=0.024)$ and $0.65 \mu \mathrm{m}(\mathrm{p}=0.013)$, respectively, for $1 \mathrm{~kg}$ of reduced HGS. The HGS was significantly related to RT in at least one group in each region except the outer inferior, the inner inferior, nasal and temporal. There was a statistically significant correlation between HGS and CT in at least one group in each region, except in the outer superior region (table 4).

Table 5 shows the relationship between peripapillary retinal nerve fibre (pRNFL) thickness and grip strength. After adjusting for other factors, the reduced grip strength was significantly associated with lower measurements of average and inferior pRNFL thickness. In addition, the multivariable regression analyses were performed to further adjusting for genotypes of rs2228570 and other factors, and the results were consistent (online supplementary table 1).

\section{DISCUSSION}

This cross-sectional study reported the association existing between HGS and diabetes, analysing RT and CT. Authors stratified the HGS results in four groups, and all the analyses were conducted explaining the differences between these groups that included a large population aged between 30 and 80 years. Multivariate analysis suggested that lower HGS in patients with diabetes without DR was independently associated with thinner RT and CT.

HGS has been shown to be an indicator of ageing. ${ }^{18} \mathrm{~A}$ decrease in HGS associated with ageing correlates with the development of age-related disorders. ${ }^{19}$ Multiple studies have explored the association between HGS and cardiovascular diseases, cognition and all-cause mortality. ${ }^{56 \text { 20-23 }}$ In addition to age, the results showed that HGS is also associated with gender, height and weight. ${ }^{24}$ Therefore, these factors were adjusted in the analysis. The thinning of the retina and choroid was also related to ageing, which can seriously affect the visual function in patients, and it can even lead to blindness. ${ }^{25}$

The underling mechanism of the associations of reduced HGS with thinner retinal or choroidal layers was elusive. A possible explanation for this may be the common risk factors and pathways between ocular and muscle sarcopenia, such as the blood vessels linking them. 
Table 4 Association of grip strength and choroidal thickness by multivariate linear regression analyses

\begin{tabular}{|c|c|c|c|c|c|c|}
\hline \multirow[b]{2}{*}{ Choroidal thickness } & \multicolumn{3}{|l|}{ Model 1* } & \multicolumn{3}{|l|}{ Model 2† } \\
\hline & Coefficient & $95 \% \mathrm{Cl}$ & $P$ value & Coefficient & $95 \% \mathrm{Cl}$ & $P$ value \\
\hline \multicolumn{7}{|l|}{ Average, $\mu \mathrm{m}$} \\
\hline Quantile 2 & 13.37 & (1.43 to 25.31$)$ & 0.028 & 13.51 & (2.26 to 24.75$)$ & 0.019 \\
\hline Quantile 3 & 3.66 & $(-8.98$ to 16.31$)$ & 0.570 & 1.66 & $(-10.26$ to 13.58$)$ & 0.784 \\
\hline Per $1 \mathrm{~kg}$ increase & 0.57 & (0.03 to 1.11$)$ & 0.037 & 0.65 & (0.13 to 1.16$)$ & 0.013 \\
\hline \multicolumn{7}{|l|}{ Central field, $\mu \mathrm{m}$} \\
\hline Quantile 1 & & 1.00 (Ref) & & & 1.00 (Ref) & \\
\hline Quantile 2 & 13.00 & (-0.82 to 26.83$)$ & 0.065 & 13.47 & (0.50 to 26.45$)$ & 0.042 \\
\hline Quantile 3 & 1.02 & $(-13.63$ to 15.66$)$ & 0.892 & -1.39 & $(-15.14$ to 12.35$)$ & 0.842 \\
\hline Quantile 1 & & 1.00 (Ref) & & & 1.00 (Ref) & \\
\hline Quantile 2 & 5.65 & $(-6.56$ to 17.87$)$ & 0.364 & 5.01 & $(-6.78$ to 16.80$)$ & 0.405 \\
\hline Quantile 3 & 0.89 & $(-12.05$ to 13.83$)$ & 0.893 & -1.34 & $(-13.84$ to 11.15$)$ & 0.833 \\
\hline Quantile 4 & 10.78 & $(-3.54$ to 25.11$)$ & 0.140 & 13.60 & $(-0.32$ to 27.51$)$ & 0.055 \\
\hline Per $1 \mathrm{~kg}$ increase & 0.39 & $(-0.16$ to 0.94$)$ & 0.167 & 0.47 & $(-0.07$ to 1.00$)$ & 0.088 \\
\hline \multicolumn{7}{|l|}{ Outer inferior, $\mu \mathrm{m}$} \\
\hline Quantile 1 & & 1.00 (Ref) & & & 1.00 (Ref) & \\
\hline Quantile 2 & 16.85 & (4.29 to 29.40 ) & 0.009 & 16.59 & (4.53 to 28.65$)$ & 0.007 \\
\hline Quantile 3 & 8.24 & $(-5.55$ to 22.03$)$ & 0.241 & 7.26 & (-5.79 to 20.30$)$ & 0.275 \\
\hline Quantile 4 & 13.45 & $(-1.82$ to 28.71$)$ & 0.084 & 16.76 & (2.23 to 31.28$)$ & 0.024 \\
\hline Per $1 \mathrm{~kg}$ increase & 0.38 & $(-0.21$ to 0.97$)$ & 0.202 & 0.47 & $(-0.09$ to 1.03$)$ & 0.102 \\
\hline \multicolumn{7}{|l|}{ Outer temporal, $\mu \mathrm{m}$} \\
\hline Quantile 1 & & 1.00 (Ref) & & & 1.00 (Ref) & \\
\hline Quantile 2 & 14.00 & (3.40 to 24.60$)$ & 0.010 & 13.19 & (2.87 to 23.50$)$ & 0.012 \\
\hline Quantile 3 & 2.00 & $(-9.23$ to 13.22$)$ & 0.727 & -0.18 & $(-11.12$ to 10.75$)$ & 0.974 \\
\hline Quantile 4 & 17.94 & (5.51 to 30.36 ) & 0.005 & 20.07 & (7.90 to 32.24$)$ & 0.001 \\
\hline Per $1 \mathrm{~kg}$ increase & 0.64 & (0.16 to 1.12$)$ & 0.009 & 0.71 & (0.24 to 1.18$)$ & 0.003 \\
\hline \multicolumn{7}{|l|}{ Inner superior, $\mu \mathrm{m}$} \\
\hline Quantile 1 & & 1.00 (Ref) & & & 1.00 (Ref) & \\
\hline Quantile 2 & 8.10 & $(-5.28$ to 21.48$)$ & 0.235 & 8.11 & (-4.63 to 20.85$)$ & 0.212 \\
\hline Quantile 3 & 0.04 & $(-14.13$ to 14.21$)$ & 0.996 & -2.23 & $(-15.73$ to 11.28$)$ & 0.746 \\
\hline Quantile 4 & 13.39 & $(-2.29$ to 29.08$)$ & 0.094 & 16.60 & (1.56 to 31.64$)$ & 0.031 \\
\hline Per $1 \mathrm{~kg}$ increase & 0.48 & $(-0.13$ to 1.08$)$ & 0.122 & 0.55 & $(-0.03$ to 1.13$)$ & 0.062 \\
\hline \multicolumn{7}{|l|}{ Inner inferior, $\mu \mathrm{m}$} \\
\hline Quantile 1 & & 1.00 (Ref) & & & 1.00 (Ref) & \\
\hline
\end{tabular}


Table 4 Continued

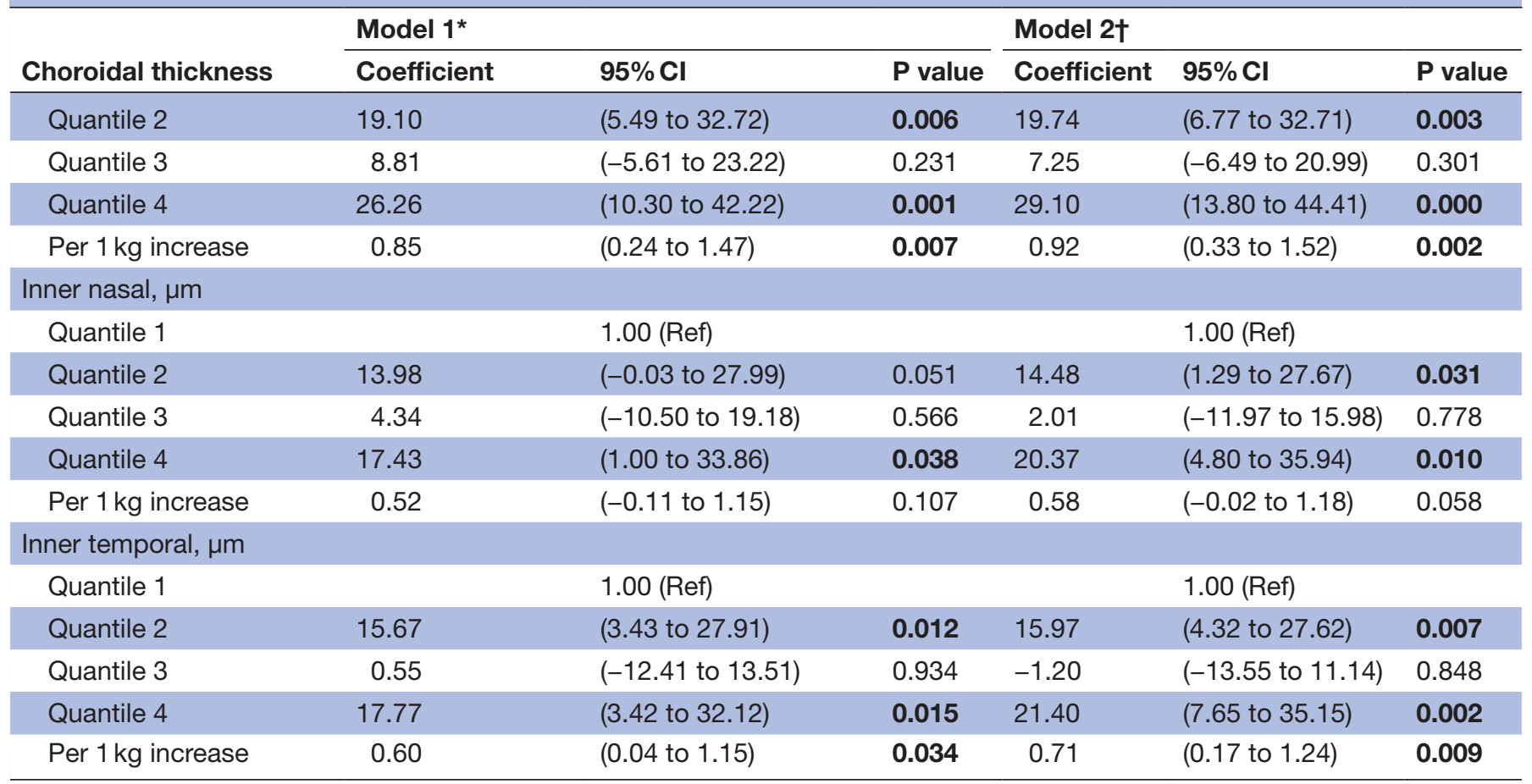

Bold indicates statistically significant.

*Model 1: adjusted for age and sex.

†Model 2: adjusted for age, gender, axial length, haemoglobin A1c, diabetes duration, use of insulin, height, weight, systolic blood pressure and diastolic blood pressure.

The retina and choroid contain a significant number of blood vessels, especially the choroid. ${ }^{26}$ Their thickness often varies greatly depending on the filling state of the blood vessels. Blood vessels are centres for transporting oxygen and nutrients. Thinning of the retina and choroid indicates a decrease in the density and velocity of blood, thus affecting the delivery of oxygen and nutrients to muscles. ${ }^{27}$ It leads to a weakening of muscle strength, which is reflected in the decline in a patient's HGS. In addition, patients with diabetes had accelerated ageing process, which leads to loss of muscle strength. The presence and severity of diabetic neuropathy were related to gradual loss of muscle strength and also related to RT and CT. Diabetic nephropathy contributed to loss of muscle strength, and altered RT and CT is a hallmark of renal function in patients with diabetes.

This finding has important implications for the development of methods for earlier diagnosis of diabetic retinal and choroidal changes. Compared with the OCT examination, HGS measurement is easy, simple and inexpensive, which makes it an economically viable method used in the early evaluation of the progress of fundus lesions in patients with diabetes and to monitor their health status. ${ }^{23} 28$ Thus, HGS may provide a valuable indicator of retinal status in patients with diabetes. In addition, the present study is the first to identify an association between HGS and RT or CT. It is a new direction for future research on HGS.
This study has some advantages. The subjects covered a wide range of ages, which differs from most previous studies on grip strength that focused on the elderly. The subjects in this study ranged from 30 to 80 years old, with an average age of $64.5 \pm 7.7$ years. Moreover, the HGS was measured by the dynamometer, which has been recommended as a standard tool for HGS testing by the American Society of Hand Therapy (ASHT) and is considered to be the gold standard for HGS testing. The thickness of the retina and choroid was obtained by the same experienced technician using the latest SS-OCT to ensure that the results are accurate and reliable. However, further study with larger sample sizes is warranted to confirm or refute our findings.

There are several limitations associated with this result. First, this study only measured the HGS and not more sophisticated parameters of muscle quality. However, HGS is a simple and easily administrated measurement in the epidemiologic and community-based study, and HGS has been shown to be an excellent indicator for muscle quality and sarcopenia. Second, investigators have just begun to explore the association of HGS and RT or CT, and more information is needed to gain a better understanding of the connection between them. This study did not explore the long-term impact of HGS changes on RT and CT or track the progress of diabetes and ocular diseases in each patient. Third, all of the patients were Chinese in urban area, thus it is difficult to extend the 
Table 5 Association of grip strength and pRNFL thickness by multivariate linear regression analyses

\begin{tabular}{|c|c|c|c|c|c|c|}
\hline \multirow[b]{2}{*}{ pRNFL thickness, $\mu \mathrm{m}$} & \multicolumn{3}{|l|}{ Model 1* } & \multicolumn{3}{|l|}{ Model $2 \dagger$} \\
\hline & Coefficient & $95 \% \mathrm{Cl}$ & $P$ value & Coefficient & $95 \% \mathrm{Cl}$ & $P$ value \\
\hline \multicolumn{7}{|l|}{ Average } \\
\hline Quantile 1 & & 1.00 (Ref) & & & 1.00 (Ref) & \\
\hline Quantile 2 & 3.83 & (1.56 to 6.11$)$ & 0.001 & 3.43 & (1.21 to 5.66 ) & 0.003 \\
\hline Quantile 3 & 4.94 & (2.54 to 7.34 ) & $<0.001$ & 3.88 & (1.53 to 6.23 ) & 0.001 \\
\hline Quantile 4 & 5.91 & (3.25 to 8.56$)$ & $<0.001$ & 5.03 & (2.42 to 7.64 ) & $<0.001$ \\
\hline Per $1 \mathrm{~kg}$ increase & 0.22 & (0.12 to 0.32$)$ & $<0.001$ & 0.18 & (0.08 to 0.28$)$ & $<0.001$ \\
\hline \multicolumn{7}{|l|}{ Superior } \\
\hline Quantile 1 & & 1.00 (Ref) & & & 1.00 (Ref) & \\
\hline Quantile 2 & -1.61 & $(-5.28$ to 2.06$)$ & 0.389 & -0.73 & (-4.26 to 2.81$)$ & 0.687 \\
\hline Quantile 3 & -2.83 & (-6.70 to 1.05$)$ & 0.152 & -3.13 & (-6.86 to 0.60$)$ & 0.100 \\
\hline Quantile 4 & -0.17 & (-4.48 to 4.14$)$ & 0.938 & -0.18 & (-4.35 to 3.99$)$ & 0.932 \\
\hline Per $1 \mathrm{~kg}$ increase & 0.01 & $(-0.15$ to 0.18$)$ & 0.894 & 0.00 & $(-0.17$ to 0.16$)$ & 0.954 \\
\hline \multicolumn{7}{|l|}{ Inferior } \\
\hline Quantile 1 & & 1.00 (Ref) & & & 1.00 (Ref) & \\
\hline Quantile 2 & 8.57 & (4.00 to 13.14 ) & $<0.001$ & 7.26 & (2.83 to 11.69 ) & 0.001 \\
\hline Quantile 3 & 12.88 & (8.07 to 17.69 ) & $<0.001$ & 10.16 & (5.48 to 14.83 ) & $<0.001$ \\
\hline Quantile 4 & 15.89 & (10.58 to 21.20$)$ & $<0.001$ & 14.28 & (9.09 to 19.46 ) & $<0.001$ \\
\hline Per $1 \mathrm{~kg}$ increase & 0.59 & (0.39 to 0.79 ) & $<0.001$ & 0.51 & (0.31 to 0.70$)$ & $<0.001$ \\
\hline \multicolumn{7}{|l|}{ Nasal } \\
\hline Quantile 1 & & 1.00 (Ref) & & & 1.00 (Ref) & \\
\hline Quantile 2 & 2.56 & $(-0.42$ to 5.53$)$ & 0.092 & 1.23 & $(-1.74$ to 4.19$)$ & 0.417 \\
\hline Quantile 3 & 2.05 & $(-1.09$ to 5.20$)$ & 0.201 & 0.97 & $(-2.16$ to 4.10$)$ & 0.543 \\
\hline Quantile 4 & 4.62 & (1.07 to 8.16$)$ & 0.011 & 3.00 & (-0.56 to 6.55$)$ & 0.098 \\
\hline Per $1 \mathrm{~kg}$ increase & 0.19 & (0.06 to 0.33 ) & 0.005 & 0.13 & $(-0.01$ to 0.26$)$ & 0.070 \\
\hline \multicolumn{7}{|l|}{ Temporal } \\
\hline Quantile 1 & & 1.00 (Ref) & & & 1.00 (Ref) & \\
\hline Quantile 2 & 0.94 & $(-2.28$ to 4.16$)$ & 0.566 & 1.37 & $(-1.83$ to 4.56$)$ & 0.402 \\
\hline Quantile 3 & 1.16 & $(-2.23$ to 4.56$)$ & 0.501 & 1.30 & (-2.08 to 4.67$)$ & 0.452 \\
\hline Quantile 4 & -0.80 & (-4.57 to 2.98$)$ & 0.680 & -0.55 & (-4.32 to 3.22$)$ & 0.775 \\
\hline Per $1 \mathrm{~kg}$ increase & 0.01 & (-0.13 to 0.16$)$ & 0.887 & 0.02 & $(-0.13$ to 0.17$)$ & 0.788 \\
\hline
\end{tabular}

Bold indicates statistically significant.

*Model 1: adjusted for age and sex.

†Model 2: adjusted for age, gender, axial length, haemoglobin A1c, diabetes duration, use of insulin, height, weight, systolic blood pressure and diastolic blood pressure.

pRNFL, peripapillary retinal nerve fibre.

results to other ethnicities and subjects in rural area. Fourth, the findings may not generalise to types 1 diabetes mellitus and patients with DR. Finally, the vitamin D levels were determined in this study. The associations remain significant after adjusting for polymorphism of vitamin D receptors, indicating that our results were robust and reliable. However, the rs2228570 could not reflect the fluctuations of $25(\mathrm{OH}) \mathrm{D}$, and further studies are warranted to evaluate the relationship between $25(\mathrm{OH}) \mathrm{D}$ and OCT parameters.

\section{CONCLUSION}

In summary, HGS was significantly associated with RT and CT in this population. Reduced HGS was found to be significantly associated with thinner RT and CT in patients with diabetes without DR, and HGS may provide an easily administered marker of retinal status in patients with diabetes.

Contributors WW, YL and WH designed and conducted the study; ZQ, WW, YT, $\mathrm{MH}, \mathrm{LW}, \mathrm{XG}, \mathrm{YL}$ and WH contributed to collection, management, analysis and 
interpretation of the data; ZQ, WW and WH prepared the manuscript; all authors reviewed and finally approved the manuscript.

Funding This research was supported in part by the National Natural Science Foundation of China (81570843; 81900866), the Guangdong Province Science \& Technology Plan (2017KYPJ094).

Competing interests None declared.

Patient and public involvement Patients and/or the public were not involved in the design, or conduct, or reporting, or dissemination plans of this research.

Patient consent for publication Not required.

Ethics approval The protocol was approved by the Committee of Zhongshan Ophthalmic Center (protocol number IRB\#2017-05-0621).

Provenance and peer review Not commissioned; externally peer reviewed.

Data availability statement Data are available upon reasonable request.

Open access This is an open access article distributed in accordance with the Creative Commons Attribution Non Commercial (CC BY-NC 4.0) license, which permits others to distribute, remix, adapt, build upon this work non-commercially, and license their derivative works on different terms, provided the original work is properly cited, appropriate credit is given, any changes made indicated, and the use is non-commercial. See: http://creativecommons.org/licenses/by-nc/4.0/.

ORCID iD

Wei Wang http://orcid.org/0000-0002-5273-3332

\section{REFERENCES}

1 Valencia WM, Florez $\mathrm{H}$. How to prevent the microvascular complications of type 2 diabetes beyond glucose control. BMJ 2017;356:i6505.

2 NCD Risk Factor Collaboration (NCD-RisC). Worldwide trends in diabetes since 1980: a pooled analysis of 751 population-based studies with 4.4 million participants. Lancet 2016;387:1513-30.

3 Yau JWY, Rogers SL, Kawasaki R, et al. Global prevalence and major risk factors of diabetic retinopathy. Diabetes Care 2012;35:556-64.

4 Leasher JL, Bourne RRA, Flaxman SR, et al. Global estimates on the number of people blind or visually impaired by diabetic retinopathy: a meta-analysis from 1990 to 2010. Diabetes Care 2016;39:1643-9.

5 Celis-Morales CA, Welsh P, Lyall DM, et al. Associations of grip strength with cardiovascular, respiratory, and cancer outcomes and all cause mortality: prospective cohort study of half a million UK Biobank participants. BMJ 2018;361:k1651.

6 Celis-Morales CA, Petermann F, Hui L, et al. Associations between diabetes and both cardiovascular disease and all-cause mortality are modified by grip strength: evidence from UK Biobank, a prospective population-based cohort study. Diabetes Care 2017;40:1710-8.

7 Ntuk UE, Celis-Morales CA, Mackay DF, et al. Association between grip strength and diabetes prevalence in black, South-Asian, and white European ethnic groups: a cross-sectional analysis of 418656 participants in the UK Biobank study. Diabet. Med. 2017;34:1120-8.

$8 \mathrm{Hu} \mathrm{S}, \mathrm{Gu} \mathrm{Y,} \mathrm{Lu} \mathrm{Z,} \mathrm{et} \mathrm{al.} \mathrm{Relationship} \mathrm{between} \mathrm{grip} \mathrm{strength} \mathrm{and}$ prediabetes in a large-scale adult population. Am J Prev Med 2019;56:844-51.

9 Fukuda T, Bouchi R, Takeuchi T, et al. Association of diabetic retinopathy with both sarcopenia and muscle quality in patients with type 2 diabetes: a cross-sectional study. BMJ Open Diab Res Care 2017;5:e000404.

10 Sumukadas D, McMurdo M, Pieretti I, et al. Association between retinal vasculature and muscle mass in older people. Arch Gerontol Geriatr 2015;61:425-8.

11 Klein R, Klein BEK, Knudtson MD. Frailty and age-related macular degeneration: the Beaver dam eye study. Am J Ophthalmol 2005;140:129-31.

12 Tan K-A, Gupta P, Agarwal A, et al. State of science: choroidal thickness and systemic health. Surv Ophthalmol 2016;61:566-81.

13 Ferrara D, Waheed NK, Duker JS. Investigating the choriocapillaris and choroidal vasculature with new optical coherence tomography technologies. Prog Retin Eye Res 2016;52:130-55.

14 Melancia D, Vicente A, Cunha JP, et al. Diabetic choroidopathy: a review of the current literature. Graefes Arch Clin Exp Ophthalmol 2016;254:1453-61.

$15 \mathrm{Kim} \mathrm{M}$, Ha MJ, Choi SY, et al. Choroidal vascularity index in type-2 diabetes analyzed by swept-source optical coherence tomography. Sci Rep 2018;8:70.

16 Nomura T, Ishiguro T, Ohira M, et al. Diabetic polyneuropathy is a risk factor for decline of lower extremity strength in patients with type 2 diabetes. J Diabetes Investig 2018;9:186-92.

17 Wang W, He M, Zhong X. Sex-Dependent choroidal thickness differences in healthy adults: a study based on original and synthesized data. Curr Eye Res 2018;43:796-803.

18 Khanna RC, Murthy GVS, Marmamula S, et al. Longitudinal Andhra Pradesh eye disease study: rationale, study design and research methodology. Clin Experiment Ophthalmol 2016;44:95-105.

19 Ma T, Lu D, Zhu Y-S, et al. Actn3 genotype and physical function and frailty in an elderly Chinese population: the Rugao longevity and ageing study. Age Ageing 2018;47:416-22.

20 Yates T, Zaccardi F, Dhalwani NN, et al. Association of walking PACE and handgrip strength with all-cause, cardiovascular, and cancer mortality: a UK Biobank observational study. Eur Heart $J$ 2017;38:3232-40.

21 Celis-Morales CA, Lyall DM, Anderson J, et al. The association between physical activity and risk of mortality is modulated by grip strength and cardiorespiratory fitness: evidence from 498135 UKBiobank participants. Eur Heart J 2017;38:116-22.

22 Firth J, Stubbs B, Vancampfort D, et al. Grip strength is associated with cognitive performance in schizophrenia and the general population: a UK Biobank study of 476559 participants. Schizophr Bull 2018;44:728-36.

23 Yeung CHC, Au Yeung SL, Fong SSM, et al. Lean mass, grip strength and risk of type 2 diabetes: a bi-directional Mendelian randomisation study. Diabetologia 2019;62:789-99.

24 Spruit MA, Sillen MJH, Groenen MTJ, et al. New normative values for handgrip strength: results from the UK Biobank. J Am Med Dir Assoc 2013;14:775.e5-775.e11.

25 Shao L, Xu L, Wei WB, et al. Visual acuity and subfoveal choroidal thickness: the Beijing eye study. Am J Ophthalmol 2014;158:702-9.

26 Nickla DL, Wallman J. The multifunctional choroid. Prog Retin Eye Res 2010;29:144-68.

27 Schuster AK, Leuschner A, Feretos C, et al. Choroidal thickness is associated with cardiovascular risk factors and cardiac health: the Gutenberg health study. Clin Res Cardiol 2020;109:172-182.

28 Kim Y, Wijndaele K, Lee D-C, et al. Independent and joint associations of grip strength and adiposity with all-cause and cardiovascular disease mortality in 403,199 adults: the UK Biobank study. Am J Clin Nutr 2017;106:ajcn156851-82. 